\title{
Las normas internacionales del trabajo sobre la negociación colectiva en los servicios públicos $\left.{ }^{*}\right)$
}

\section{International labor standards concerning collective bargaining in public services}

\author{
Miguel Francisco Canessa Montejo(**) \\ Universidad Carlos III de Madrid
}

\begin{abstract}
Resumen: Las normas internacionales del trabajo reconocen el derecho de negociación colectiva de los funcionarios y los servidores públicos, pudiendo excluir solo a los funcionarios públicos de alto nivel (con poder de decisión, desempeñan cargos directivos o de confianza) y los miembros de las fuerzas armadas y la policía. Las materias de la negociación cubren las condiciones de trabajo y de empleo, que incluye la negociación salarial. El principio de equilibrio presupuestal es un límite válido a la negociación colectiva.
\end{abstract}

Palabras clave: Derecho Laboral - Negociación colectiva - Administración Pública Funcionarios públicos - Normas internacionales del trabajo

Abstract: International Labor Standards recognize the right to collective bargaining of public servants and officials, allowing for the exclusion of high-level employees (with policy-making power, managerial positions or positions based on trust) and members of the armed forces and police. The negotiation topics cover the conditions of work and employment, which includes salary negotiation. The principle of budget balance is a valid limit to collective bargaining.

Keywords: Labour Law - Collective bargaining - Public services - Public servants International Labor Standards

(") Nota del Editor: este artículo fue recibido el 3 de febrero del 2019 y su publicación fue aprobada el 14 de marzo de 2019.

$\left({ }^{* *}\right)$ Profesor universitario y consultor internacional. Abogado y Sociólogo por la Pontificia Universidad Católica del Perú. Doctor en Derecho por la Universidad Carlos III de Madrid. Correo electrónico: mcanessa@pucp.edu.pe. 


\section{Introducción}

La negociación colectiva en el sector público es la materia más recurrente en el debate jurídico laboral nacional, más aún en el contexto de expedirse una pronta legislación que responda a la exigencia del Tribunal Constitucional sobre la materia. Sin embargo, el debate nacional viene dejando de lado las obligaciones internacionales que tiene nuestro país con la ratificación de los Convenios No. 87, 98 y 151 de la Organización Internacional del Trabajo (OIT). Esto se explica por el desconocimiento del contenido del derecho de negociación colectiva en el sector público establecido en las normas internacionales del trabajo vinculantes para nuestro país.

Basta recordar que el Tribunal Constitucional reiteradamente subraya que los convenios de la Organización Internacional del Trabajo sobre negociación colectiva forman parte del bloque de constitucionalidad. Desde esta relevante posición constitucional ponemos el énfasis en el Derecho Internacional del Trabajo como aporte jurídico al contenido del derecho estudiado.

El presente artículo pretende ser un aporte en este debate desde una lectura de las normas internacionales del trabajo y los pronunciamientos de los órganos de control de la OIT: la Comisión de Expertos y el Comité de Libertad Sindical.

Para ello, lo hemos dividido en dos partes. La primera parte aborda el ámbito de aplicación de las normas internacionales del trabajo sobre la negociación colectiva en los servicios públicos. De este modo, señalar el alcance del derecho de negociación colectiva en los servicios públicos conforme a las normas internacionales del trabajo, y precisar la titularidad de los empleados públicos del derecho de negociación colectiva a partir de los pronunciamientos de los órganos de control de la OIT. La segunda parte estudia las materias de la negociación colectiva y sus limitaciones.

El diseño del artículo no se plantea en términos de una hipótesis por corroborar o rechazar, sino más bien adopta una metodología que pone el énfasis en discernir sobre el contenido de las categorías jurídicas; es decir, pretender ser un artículo conceptual.

\section{Primera Parte: el alcance del derecho de negociación colectiva en los servicios públicos}

El reconocimiento efectivo del derecho de negociación colectiva en los servicios públicos en la OIT tiene su fundamento en su propia Constitución y la Declaración de Filadelfia, como lo resalta la Declaración de la OIT sobre los principios y derechos fundamentales en el trabajo de 1998 (en adelante, la Declaración de 1998).

En efecto, la Constitución de la OIT, la parte XIII del Tratado de Versalles (1919), reconoce en su Preámbulo el principio de libertad sindical y la Declaración de Filadelfia (1944) establece la obligación solemne del organismo internacional de fomentar el reconocimiento efectivo del derecho de negociación colectiva entre los Estados Miembros. Asimismo, los órganos de control han expresado reiteradamente que el derecho de negociación colectiva forma parte del principio de libertad sindical (OIT 2018, párr. 1232).

Así, la Declaración de 1998 recuerda: "que, al incorporarse libremente a la OIT, todos los Miembros han aceptado los principios y derechos enunciados en su Constitución y en la Declaración de Filadelfia, y se han comprometido a esforzarse por lograr los objetivos generales de la Organización en toda la medida de sus posibilidades y atendiendo a sus condiciones específicas". Además, la propia Declaración de 1998 declara: "que todos los Miembros, aun cuando no hayan ratificado los convenios aludidos ${ }^{(1)}$, tienen un compromiso que se deriva de una mera pertenencia a la Organización de respetar, promover y hacer realidad, de buena fe y de conformidad con su Constitución, los principios relativos a los derechos fundamentales que son objetos de esos convenios".

Por ende, existe la obligación de los Estados Miembros de la OIT en respetar, promover y hacer realidad el principio de libertad sindical, que incluye el derecho de negociación colectiva, al interior de los ordenamientos nacionales, aunque no hayan ratificado ninguno de los dos convenios fundamentales en la materia: el Convenio No. 87 sobre la libertad sindical y la protección del derecho de sindicación y el Convenio No. 98 sobre el derecho de sindicación y de negociación colectiva(2).

(1) La Declaración de 1998 se refiere a los ocho convenios fundamentales de la OIT

(2) En la actualidad, el Convenio No. 87 no ha sido ratificado por treinta y dos Estados miembros y el Convenio No. 98, por veintidós Estados miembros. Nuestro país ha ratificado ambos. 
Las normas internacionales del trabajo que abordan el derecho de negociación colectiva cumplen el rol de precisar el contenido y el alcance del principio de libertad sindical en esta materia.

Por primera vez fue formulado expresamente el derecho de negociación colectiva en una norma internacional del trabajo en el artículo 3 del Convenio No. 84 sobre el derecho de asociación (territorios no metropolitanos)(3) al señalar que: "Se deberán dictar todas las medidas pertinentes a fin de garantizar a los sindicatos representativos de los trabajadores interesados el derecho a celebrar contratos colectivos con los empleadores o con las organizaciones de empleadores" (la cursiva es mía).

Posteriormente, el Convenio No. 98 sobre el derecho de sindicación y el derecho de negociación colectiva (1949) establece en su artículo 4: "Deberán adoptarse las medidas adecuadas a las condiciones nacionales, cuando ello sea necesario, para estimular y fomentar entre los empleadores y las organizaciones de empleadores, por una parte, y las organizaciones de trabajadores, por otra, el pleno desarrollo y uso de procedimientos de negociación voluntaria, con el objeto de reglamentar, por medio de contratos colectivos, las condiciones de empleo" (la cursiva es mía).

El mismo Convenio establece en su artículo 6 su marco de aplicación dentro de los servicios públicos en estos términos: "El presente Convenio no trata de la situación de los funcionarios públicos en la administración del Estado y no deberá interpretarse, en modo alguno, en menoscabo de sus derechos o de su estatuto".

La norma internacional establece como regla general que no se aplica el Convenio No. 98 a los funcionarios públicos que laboran en la administración del Estado, por lo que si la normativa nacional les reconoce el derecho de negociación colectiva a los funcionarios públicos no puede interpretarse que esta regulación se opone a ello.

Asimismo, la norma internacional solo se refiere a los funcionarios públicos por lo que no puede interpretarse que la exclusión del Convenio No. 98 apunta a todos los empleados públicos. Esta interpretación se sustenta en los trabajos preparatorios de la elaboración de la norma internacional, así se señala:

"Pero al excluir de la aplicación de la reglamentación solamente a los funcionarios al servicio de las administraciones públicas, debía entenderse que, por oposición, todos los trabajadores, incluyendo a los obreros y a los empleados al servicio de las administraciones públicas que no gozasen del estatuto de funcionarios, habrían de beneficiarse de la eventual reglamentación internacional" (OIT 1949, 31).
Sobre la base de esta interpretación del artículo 6 del Convenio No. 98, la Comisión de Expertos lo ahonda en los siguientes términos:

"En lo que atañe a los funcionarios a los que se les aplica sin distinción el Convenio núm 87, el artículo 6 del Convenio No. 98 establece que el Convenio no trata de la situación de los funcionarios públicos y no deberá interpretarse, en modo alguno, en menoscabo de sus derechos o de su estatuto. La Comisión estima que, si bien cabe admitir que el concepto de funcionario público varía en cierta medida según los sistemas jurídicos, la exclusión del campo de aplicación del Convenio de las personas empleadas por el Estado o en el sector público, pero que no actúen como órganos del poder público (aunque se les haya conferido un estatuto idéntico al de los funcionarios públicos que ejercen actividades propias de la administración del Estado), es contraria al sentido del Convenio; la Comisión considera también que este sentido se refleja en forma más clara todavía en el texto en inglés del artículo 6 del Convenio, el cual autoriza solamente la exclusión de los funcionarios "engaged in the administration of the State" (es decir, empleados de la administración del Estado). En efecto, la Comisión no puede aceptar que categorías importantes de trabajadores empleados por el Estado queden excluidas de los beneficios del Convenio por el mero hecho de estar formalmente asimiladas a ciertos funcionarios públicos que ejercen actividades propias de la administración del Estado. Si así fuera, el alcance del Convenio podría quedar limitado en forma considerable. Conviene, pues, establecer una distinción entre los funcionarios que ejercen actividades propias de la administración del Estado (funcionarios de los ministerios y demás organismos gubernamentales comparables) y los funcionarios que actúan en calidad de auxiliares de los precedentes, por una parte, y las demás personas empleadas por el Estado, las empresas públicas o las instituciones públicas autónomas, por otra.

(3) El Convenio No. 84 ha sido ratificado por nueve Estados miembros. 
Sólo podría excluirse del campo de aplicación del Convenio a la primera categoría de trabajadores a que se ha hecho referencia" (OIT 1983, párr. 255).

El órgano de control reconoce que los ordenamientos nacionales definen a los funcionarios públicos de manera distinta, justamente esta disparidad le obliga a la Comisión constreñir la definición de funcionario público de modo que no excluya arbitrariamente a empleados públicos. El criterio expuesto es que son funcionarios públicos los que ejercitan las actividades propias de la administración del Estado. Esto le permite señalar que no es conforme al Convenio No. 98 excluir a los auxiliares de los funcionarios públicos, los trabajadores de las empresas públicas, los trabajadores de las institucionales públicas autónomas, etc.

En cambio, el artículo 5 del Convenio No. 98 en el párrafo 1 otorga a la legislación nacional la potestad de determinar el alcance de las garantías previstas en lo que se refiere a la aplicación a las fuerzas armadas y a la policía. Esta regulación continúa con lo prescrito por el artículo 9 párrafo 1 del Convenio No. 87 sobre la libertad sindical y la protección del derecho de sindicación donde también otorga la potestad a la legislación nacional determinar si se les aplica las garantías establecidas por la norma internacional.

Si bien la mayoría de los Miembros de la OIT excluyen a los componentes de las fuerzas armadas y de la policía en la titularidad del derecho de negociación colectiva, existe una tendencia entre los países por reconocerles este derecho, especialmente a la policía (OIT 2013, párr. 252)(4). No obstante, carece de sustento extender las excepciones a otra categoría de trabajadores. Como bien señala la Comisión, estas excepciones deben interpretarse en un sentido restrictivo (OIT 2012, párr. 67).

En conclusión, el Convenio No. 98 excluye de su aplicación a los funcionarios públicos en la administración del Estado, permitiendo en el caso de los miembros de las fuerzas armadas y la policía que la legislación nacional establezca su tratamiento normativo. Esta exclusión debe ser interpretada restrictivamente, por lo que los demás empleados públicos tienen el derecho a la negociación colectiva en el marco del Convenio No. 98.

Ante las dificultades del ejercicio de la libertad sindical en los servicios públicos, la OIT adopta el Convenio No. 151 sobre las relaciones de trabajo en la administración pública (1978) con el objetivo de completar el Convenio No. 98 en este sector. En su Preámbulo se subraya:

"Los problemas particulares que plantea la delimitación del campo de aplicación de un instrumento internacional y la adopción de definición a los fines del instrumento en razón de las diferencias existentes en muchos países entre el empleo público y el empleo privado, así como las dificultades de interpretación que se han planteado a propósito de la aplicación de los funcionarios de las disposiciones pertinentes del Convenio sobre el derecho de sindicación y de negociación colectiva, 1949, y las observaciones por las cuales los órganos de control de la OIT han señalado en diversas ocasiones que ciertos gobiernos han aplicado dichas disposiciones en forma tal que grupos numerosos de empleados públicos han quedado excluidos del campo de aplicación del Convenio."

Por ello, el Convenio No. 151 aborda la definición de los empleados públicos en su regulación. El artículo 1 párrafo 2 señala que: "La legislación nacional deberá determinar hasta qué punto las garantías previstas en el presente Convenio se aplican a los empleados de alto nivel que, por sus funciones, se considera normalmente que poseen poder decisorio o desempeñan cargos directivos o a los empleados cuyas obligaciones son de naturalmente confidencial". Definiendo entre los artículos 1 y 2 que el empleado público es toda persona empleada por la administración pública.

Una lectura conjunta de los Convenios No. 98 y 151 sobre las expresiones empleado público y funcionario público alude a que el primero se refiere a la generalidad de personas que laboran en el Estado, mientras que el segundo se refiere solo a aquellos que cumplen una función especial dentro de la administración del Estado. En otras palabras, el empleado público es el término general y el funcionario público es una especie de aquél. Dentro de este último grupo, solo los funcionarios públicos de alto nivel pueden ser exceptuados del derecho. Para fundamentar esta interpretación recurrimos al mencionado artículo 1 párrafo 2 del Convenio No. 151 cuando señala que un empleado público por sus funciones se le considera de alto nivel, es decir, las funciones específicas que ejercen lo elevan a ese nivel.

(4) Por ejemplo, Estonia les reconoce tanto a los miembros de las fuerzas armadas y a los de la policía el derecho de negociación colectiva. En cambio, Australia solo se lo reconoce a la policía y lo excluye a los miembros de las fuerzas armadas. 
De este modo, el Convenio No. 151 asegura que solo los funcionarios públicos de alto nivel pueden ser excluidos válidamente del derecho de negociación colectiva por la legislación nacional. El Convenio No. 151 identifica tres tipos de funcionarios públicos de alto nivel que podrían ser excluidos en su aplicación: a) los funcionarios públicos que poseen poder de decisión, b) los funcionarios públicos que desempeñan cargos directivos, c) los funcionarios públicos de confianza.

A este listado debemos agregar a los mencionados miembros de las fuerzas armadas y la policía señalados en el Convenio No. 98 y reiterado en el artículo 1 párrafo 3 del Convenio No. 151.

Tengamos presente que el Convenio No. 151 no modifica el goce del derecho de negociación colectiva de los empleados públicos dispuesto por el Convenio No. 98 porque expresamente establece en el artículo 1 párrafo 1: "El presente Convenio deberá aplicarse a todas las personas empleadas por la administración pública, en la medida en que no le sean aplicables disposiciones más favorables de otros convenios internacionales del trabajo" (la cursiva es mía).

En conclusión, los empleados públicos gozan del derecho de negociación colectiva por el Convenio No. 98, mientras este derecho se le reconoce a los funcionarios públicos por el Convenio No. 151, salvo para los funcionarios de alto nivel que pueden ser exceptuados del derecho por la legislación nacional.

Posteriormente, la OIT adopta el Convenio No. 154 sobre la negociación colectiva (1981) que se aplica a todas las ramas de la actividad económica, incluyendo la administración pública, aunque otorgando la potestad a la legislación o la práctica nacionales que podrán fijar modalidades particulares de aplicación del Convenio para este sector y determinar hasta qué punto las garantías previstas también son aplicables a las fuerzas armadas y a la policía (artículo 1).

La potestad en fijar modalidades de aplicación del Convenio No. 154 en la administración pública resulta armonioso con la excepción establecida en el Convenio No. 151 sobre la restricción del derecho de negociación colectiva de los funcionarios públicos de alto nivel. Como resalta la Comisión:

"Puesto que el Convenio No. 151 es un Convenio específicamente aplicable a los empleados públicos, la exclusión de las categorías mencionadas del derecho de negociación colectiva no infringe lo dispuesto en el Convenio No. 154, que tiene un alcance general y reconoce expresamente en el párrafo 3 del artículo 1 que, en lo que se refiere a la administración pública, la legislación y las prácticas nacionales podrán fijar modalidades particulares de aplicación" (OIT 2013a, párr. 246).

En resumen, las normas internacionales del trabajo señalan que los empleados públicos tienen el derecho de negociación colectiva, con la excepción de los funcionarios públicos de alto nivel -en los términos fijados por el Convenio No. 151- y los miembros de las fuerzas armadas y la policía, quienes podrán válidamente ser excluidos por la legislación nacional.

\subsection{La titularidad de los empleados públicos del derecho de negociación colectiva}

Los órganos de control de la OIT se pronuncian constantemente sobre la correcta aplicación de las normas internacionales del trabajo para evitar que sean indebidamente excluidos los empleados públicos. Apoyándome en esos pronunciamientos se puede elaborar un listado abierto de casos.

2.1.1. Las autoridades públicas que ocupan cargos políticos por elección o por nombramiento

Durante los trabajos preparatorios de la elaboración del Convenio No. 151 tanto en la Comisión del Servicio Público como en el debate en la Conferencia de la OIT, se discutió sobre la situación jurídica de las autoridades públicas electas o nombradas para ocupar cargos de carácter político en el marco de la norma internacional.

Se concluyó que los parlamentarios, los magistrados y otras autoridades públicas que ocupen cargos de carácter político por elección o por nombramiento se ubican dentro de la categoría de funcionarios públicos de alto nivel, por lo que pueden ser válidamente exceptuados del derecho de negociación colectiva, aunque los magistrados gozan del derecho de sindicación establecido en el Convenio No. 87 (OIT 1977, 660).

El respaldo de esta exclusión se respalda en lo mencionado sobre los tres tipos de funcionarios públicos dispuesto por el Convenio 151, en este caso son empleados públicos de alto nivel que poseen poder de dirección. Siguiendo ese criterio se podrían también incluir a los ministros, los secretarios de Estado, los directores generales y otros cargos de confianza (OIT 2013a, párr. 66). Asimismo, se podrían incluir las autoridades regionales, provinciales y locales electas.

2.1.2. Los trabajadores de la enseñanza pública

Los trabajadores de la enseñanza pública británica presentaron una queja ante el 
Comité de Libertad Sindical en razón que su Gobierno remitió un proyecto de Ley al Parlamento para restringir la negociación colectiva de este grupo. El argumento gubernamental fue que la regulación del Convenio No. 151 permitía esta exclusión.

El Comité consideró que la restricción del derecho de negociación colectiva para los trabajadores de la enseñanza pública era opuesta al Convenio No. 98 aunque se hubiese ratificado el Convenio No. 151:

"El Comité estima, por su parte, que el párrafo 1 del artículo 1 del Convenio No. 151 implica que los derechos garantizados en el Convenio No. 98 no pueden denegarse o limitarse por una simple referencia al Convenio No. 151. En el caso de un país como el Reino Unido que ha ratificado ambos Convenios y de un sector de actividad como la enseñanza pública en que ambos Convenios son aplicables conviene, pues, determinar si el artículo 4 del Convenio No. 98 contiene disposiciones más favorables a los trabajadores que el artículo 7 del Convenio No. 151, ofrece disposiciones más favorables, pues incluye la noción del recurso voluntario a la negociación y la autonomía de las partes en ella. Debería entonces aplicarse de preferencia dicho artículo con respecto al artículo 7, que incita a los poderes públicos a estimular y fomentar la negociación colectiva ya por procedimientos que permitan dicha negociación ya por cualesquiera otros métodos que permitan a los representantes de los empleados públicos participar en la determinación de sus condiciones de empleo" (CLS 1988c, párr. 85).

En otras palabras, cuando concurre la aplicación del artículo 4 del Convenio No. 98 y el artículo 7 del Convenio No. 151 , si aquél resulta más beneficioso para los trabajadores prevalece sobre éste. Este pronunciamiento del Comité no se reduce solo a los trabajadores de la enseñanza pública sino puede extenderse a los demás empleados públicos. En supra afirmamos que los empleados públicos beneficiados por el Convenio No. 98 gozan del derecho de negociación colectiva sin verse mermado su derecho por la ratificación del Convenio No. 151

En el caso específico de los docentes del sector público, la Comisión de Expertos se pronuncia reiteradamente que gozan del derecho de negociación colectiva y que su exclusión es una violación del Convenio No. 98. Por ejemplo, en su Observación sobre Etiopía, la Comisión es explícita al señalar:

"Tomando nota de que la reforma aún no ha terminado, la Comisión espera firmemente que el Gobierno redoble sus esfuerzos y adopte las medidas necesarias para asegurar que el derecho de negociación colectiva se garantiza a los funcionarios públicos que no trabajan en la administración del Estado, incluidos los docentes de las escuelas públicas" (la cursiva es mía) (OIT 2017, 124).
Para los órganos de control de la OIT no existe controversia que los trabajadores de la enseñanza pública tienen el derecho a la negociación colectiva, ya sea que solo han ratificado el Convenio No. 98, o el Convenio No. 151, o ambos.

2.1.3. Los trabajadores de la salud pública El derecho de negociación colectiva de los trabajadores de la salud pública fue discutido en el Caso 1882 ante el Comité de Libertad Sindical cuando el sindicato de enfermeras danesas presentó una queja contra su Gobierno por la Ley que prorroga los convenios colectivos vigentes sin consultar con las organizaciones sindicales.

El Comité señaló que cualquier restricción al derecho de negociación colectiva debe venir acompañado de garantías para proteger el nivel adecuado de los trabajadores afectados y que los empleados de los hospitales públicos se distinguen de los funcionarios públicos de alto nivel:

"que el artículo 6 del Convenio No. 98 permite la exclusión de este derecho básico a "los funcionarios públicos en la administración del Estado", término éste que el Comité ha contemplado a la luz de la distinción que debe trazarse entre los funcionarios empleados en diversas capacidades en los ministerios públicos $\mathrm{u}$ organismos similares y otras personas empleadas por el gobierno, por empresas públicas - como hospitales públicos, en este caso - o por organizaciones públicas independientes" (la cursiva es mía) (OIT 1988e, párr. 433).

El argumento es similar al caso de los docentes, los trabajadores de la salud pública no pueden ser considerados funcionarios públicos en la administración del Estado, conforme lo señala la exclusión del artículo 6 del Convenio No. 98 y precisado por el artículo 1 párrafo 2 del Convenio No. 151. En otras palabras, los trabajadores de la salud pública gozan del derecho de negociación colectiva.

\subsubsection{Los empleados municipales}

El derecho de negociación colectiva de los trabajadores municipales queda ejemplificado en una Observación de la Comisión de Expertos a Panamá. En la comunicación 
remitida por el Gobierno panameño dentro del sistema de reportes, le señala que conforme a su normativa los empleados municipales no cuentan con el derecho de negociación colectiva en razón que las organizaciones de servidores públicos no tienen la calidad de sindicatos. Al carecer de esta calificación no se les reconoce este derecho.

La Comisión le recuerda al Gobierno que solo se permite excluir de sus derechos y garantías, incluyendo el derecho de negociación colectiva, a las personas que trabajan en la administración del Estado, la policía y las fuerzas armadas, por lo que todos los demás funcionarios y empleados públicos deberían disfrutar del derecho de negociación colectiva.

Por ello, la Comisión le pide al Gobierno modificar la legislación para que sea acorde al Convenio (OIT 2011, 149).

2.1.5. Los trabajadores de las empresas públicas y las instituciones públicas autónomas

El Comité de Libertad Sindical ha evaluado reiteradamente quejas sindicales donde se les niega el derecho de negociación colectiva a los trabajadores estatales que laboran en empresas públicas o en instituciones públicas autónomas por considerarlos funcionarios públicos. Aquí recopilamos algunos pronunciamientos paradigmáticos que nos permiten precisar los argumentos de los órganos de control para rechazar que se les niegue el derecho de negociación colectiva a este grupo de empleados públicos.

La queja sindical contra Colombia por prohibir la negociación colectiva de los trabajadores que laboran en la empresa estatal de radio y televisión. El Comité sostiene que no puede excluirse al personal que labora en el Instituto Nacional de Radiotelevisión colombiana, en razón que por las funciones que cumplen no corresponde a la de los funcionarios públicos señalados por la norma internacional del trabajo (CLS 1988b, párr. 87).

Una situación similar ocurrió con los trabajadores jordanos de correos y telecomunicaciones, donde el Comité de Libertad Sindical recordó que la obligación de promover la negociación colectiva comprende a todos los trabajadores del Estado que no actúan como órganos del poder público (CLS 1988a, párr. 278), por lo que estos trabajadores son titulares del derecho.

En otra queja sindical colombiana presentada por el sindicato de trabajadores ferroviarios se señala que la dirección de la empresa estatal procedió a una recalificación de los trabajadores oficiales considerándolos como empleados públicos, perjudicándolos en su estabilidad en el empleo y los beneficios consagrados en convenciones colectivas. El Comité de Libertad Sindical señaló que no puede pronunciarse sobre la legalidad de la recalificación, pero "desea subrayar que desde el punto de vista de los Convenios núms. 87 y 98 el estatuto legal de los «empleados públicos», no es satisfactorio en la medida en que tales trabajadores de empresas comerciales o industriales del Estado deberían poder negociar convenciones colectivas (CLS 1988d, párr. 677).

En otro caso similar, los trabajadores del sector público de Hong Kong (en la Región Administrativa Especial de China) presentaron una queja por la reducción unilateral de sus salarios y el rechazo a entablar cualquier negociación con los sindicatos de la administración pública. Una vez más el Comité reiteró en su pronunciamiento sobre el derecho de negociación colectiva de los trabajadores estatales:

"Con respecto a los funcionarios públicos en particular, el Comité recuerda que conviene hacer una distinción entre los funcionarios que ejercen actividades propias de la Administración del Estado (funcionarios de los ministerios y demás organismos gubernamentales comparables), y los funcionarios que actúan en calidad de auxiliares de los precedentes, por una parte, y las demás personas empleadas por el Estado en las empresas públicas o en las instituciones públicas autónomas, por otra. Sólo podrá excluirse del campo de aplicación del Convenio No. 98 a la primera categoría de trabajadores a que se ha hecho referencia. Por consiguiente, todos los trabajadores del sector público no afectados a la administración del Estado deben gozar de los derechos de negociación colectiva, y se debería dar prioridad a la negociación colectiva como medio de resolver las controversias que se planteen en relación con el establecimiento de las condiciones de empleo en el sector público [...]. Así pues, la legislación debería prever disposiciones específicas en las que se reconozca clara y explícitamente el derecho de las organizaciones de empleados y funcionarios de la administración pública que no trabajan en calidad de agentes de la administración pública a concluir acuerdos colectivos" (CLS 1988f, párr. 677).

Hay que destacar dos aspectos esenciales. En primer lugar, el Comité distingue entre los 
funcionarios públicos que ejercen las actividades propias en la administración del Estado y los funcionarios públicos que cumplen labores auxiliares. Solo al primer grupo se le puede exceptuar del derecho de negociación colectiva. Con ello, este distingo subraya que la excepción no es a la generalidad de los funcionarios públicos. La excepción debe interpretarse en forma restrictiva y solo se justifica porque el funcionario público de alto nivel goza de poder decisorio o alta confianza. En segundo lugar, no puede considerarse como funcionario público de alto nivel a los empleados públicos que laboran en las empresas públicas o estatales y las instituciones públicas autónomas.

También debemos tener presente a los empleados de la administración pública con independencia del tipo de contrato, ya sea permanente o temporal, o con contrato civil o administrativo de prestación de servicios, o en régimen de tercerización, o con contrato a tiempo parcial. En todos estos supuestos, los trabajadores tienen derecho a la negociación colectiva (OIT 2013a, párr. 585).

\subsubsection{El personal de establecimientos penitenciarios}

La Ley de sobre la Función Pública de Botswana excluye de su aplicación al servicio penitenciario por calificarlo como un servicio de seguridad, equivalente a la policía. En su Observación de 2013, la Comisión le señala al Gobierno africano que:

"En virtud del artículo 1 del Convenio 151 sólo la policía, las fuerzas armadas, los agentes de nivel elevado, cuyas funciones se consideran normalmente relacionadas con la formulación de las políticas que han de seguirse o con las tareas de dirección, y los agentes cuyas responsabilidades tienen un carácter altamente confidencial, pueden quedar excluidos del ámbito de aplicación del Convenio" (OIT 2013b, 71).

Por lo que la Comisión solicita que se enmiende la Ley con el fin de garantizar que el personal del servicio penitenciario goce de los derechos consagrados en el Convenio. En otras palabras, la Ley equipara equivocadamente al personal de establecimientos penitenciarios con la policía.

Con este pronunciamiento la Comisión de Expertos aplica la interpretación restrictiva de la excepción en la titularidad del derecho de negociación colectiva. En conclusión, los trabajadores penitenciarios tienen el derecho de negociación colectiva.

2.1.7. El personal civil en las fuerzas armadas y de la policía El argumento para otorgar la potestad legislativa nacional en exceptuar a los miembros de las fuerzas armadas y de la policía del derecho de negociación colectiva en el Convenio No. 151 proviene de su función como cuerpos de seguridad del Estado. Sin embargo, este argumento no cabe extenderlo para el personal civil de las fuerzas armadas y de la policía al no cumplir dicha función. Como señala la Comisión de
Expertos, a este personal civil se le aplica el Convenio No. 151 (OIT 2013a, párr. 70), con lo que gozan del derecho de sindicación y de negociación colectiva.

Otro ejemplo lo tenemos en el caso de los técnicos de la aviación que prestan servicios dentro de la jurisdicción de las fuerzas armadas, que como señala el Comité, no pueden ser considerados pertenecientes a éstos por las tareas que cumplen (OIT 2018, párr. 1272).

2.1.8. La competencia de los órganos de control de la OIT

Estos pronunciamientos de los órganos de control de la OIT ejemplifican casos precisos de empleados públicos que no deben ser excluidos del derecho de negociación colectiva. El énfasis de la interpretación restrictiva reside en que es una excepción a la titularidad de un derecho fundamental, por lo que los pronunciamientos son precisos al respecto.

Asimismo, los órganos de control de la OIT resaltan que es una evaluación caso por caso. Esto significa que estos ejemplos reseñados ni son los únicos ni son una lista cerrada, les compete a los órganos de control resolverlo sobre la base de los criterios plasmados en las normas internacionales del trabajo:

"Corresponde a la Comisión de Expertos y al Comité de Libertad Sindical determinar, caso por caso, si se ha recurrido de forma demasiado generalizada a la noción de confidencialidad o a la calificación de tareas como de dirección o relacionadas con la toma de decisiones. Para ello, los órganos de control deben basarse en criterios como el poder de sanción de que disponen los empleados públicos en cuestión, o incluso en la determinación de en qué medida sus funciones incluyen la capacidad para emitir normas o decisiones administrativas, representar al Estado, supervisar las cuentas públicas (por ejemplo, los auditores o en ocasiones los contadores públicos), etc. Así pues, estos criterios se basan en la naturaleza de las actividades, así como en la posición que ocupan estos empleados en la jerarquía, ya que, según el Comité, tales empleados deben disponer de un grado de autonomía elevado" (OIT 2013a, párr. 65). 
Sobre la base de estos criterios interpretativos que se respaldan en el distingo entre los funcionarios públicos de alto nivel y los demás funcionarios y empleados públicos puede precisarse la titularidad del derecho de negociación colectiva en el servicio público.

\section{Segunda Parte: las materias de la negociación colectiva en el servicio público}

El análisis de las materias que comprenden la negociación colectiva en los servicios públicos, tomando en consideración sus particularidades y bajo el marco de las normas internacionales del trabajo, nos conduce a tres asuntos.

En primer lugar, el procedimiento entre las autoridades públicas competentes y las organizaciones de los empleados públicos para establecer las condiciones laborales. En segundo lugar, las materias que pueden abordarse en dicho procedimiento. En tercer lugar, la restricción presupuestaria que condiciona el resultado de dicho procedimiento. Estos tres asuntos son los que se abordan en este acápite.

\subsection{El procedimiento de negociación colectiva y de consulta en los servicios públicos}

Las normas internacionales del trabajo establecen como procedimiento predominante la negociación colectiva, pero en el caso de la administración pública también permiten alternativamente otros métodos en tanto posibiliten participar a las organizaciones de los empleados públicos en la fijación de las condiciones laborales.

El mencionado artículo 4 del Convenio No. 98 establece como finalidad estimular y fomentar el pleno desarrollo y uso de procedimientos de negociación voluntaria, con objeto de reglamentar las condiciones de empleo. Asimismo, señala que podía excluirse de estos procedimientos a los funcionarios públicos en la administración del Estado (artículo 6). Como concluimos en el apartado anterior sobre la base de los pronunciamientos de los órganos de control, los Estados Miembros de la OIT que ratificaron el Convenio No. 98 solo pueden exceptuar a los funcionarios públicos en la administración del Estado, sin desconocer que los empleados públicos tienen el derecho de procedimientos de negociación voluntaria.

Luego el Convenio No. 151 introduce en su artículo 7, al lado de la negociación colectiva, otros métodos para determinar las condiciones de empleo de los funcionarios públicos en la administración el Estado: "Deberán adoptarse de ser necesario, medidas adecuadas a las condiciones nacionales para estimular y fomentar el pleno desarrollo y utilización de procedimientos de negociación entre autoridades públicas competentes y las organizaciones de empleados públicos acerca de las condiciones de empleo, o de cualesquiera otros métodos que permitan a los representantes de los empleados públicos participar en la determinación de dichas condiciones" (la cursiva es mía).

La Comisión de Expertos analizando el artículo 7 del Convenio No. 151 sostiene al respecto:

"Esta formulación retoma principalmente el principio establecido en el artículo 4 del Convenio No. 98, con una diferencia en lo referente a los funcionarios públicos, a saber, la posibilidad de recurrir a otros métodos distintos de la negociación colectiva. La Conferencia Internacional del Trabajo permite así ampliar los derechos reconocidos por el Convenio No. 98 a los empleados públicos, otorgándoles oficialmente el derecho a participar en la determinación de sus condiciones de empleo, cuya negociación colectiva se menciona como una de las modalidades posibles" (OIT 2013a, párr. 47).

En otras palabras, el Convenio No. 151 permite que por medio de otros métodos distintos a la negociación colectiva se puedan determinar las condiciones de empleo para los funcionarios públicos en la administración del Estado.

La Recomendación No. 159 sobre las relaciones de trabajo en la administración pública (1978) señala en su párrafo 2 , apartado 2: "En el caso que existan métodos distintos de la negociación para permitir a los representantes de los empleados públicos participar en la fijación de las condiciones de empleo, el procedimiento para asegurar esa participación y para determinar de manera definitiva tales condiciones debería preverse mediante la legislación nacional o por otros medios apropiados" (la cursiva es mía). Para la norma internacional del trabajo resulta preferible que la legislación o la práctica nacional aborde expresamente estos métodos de modo que disipe cualquier duda en su aplicación.

Los órganos de control de la OIT han cumplido una tarea fundamental en concretar el contenido de los métodos distintos a la negociación directa en la definición de las condiciones de empleo de los funcionarios públicos. 
En primer lugar, se ha precisado que estos métodos distintos de la negociación son procedimientos de consulta. Así lo afirma la Comisión de Expertos: "Con respecto a los métodos distintos de la negociación colectiva para determinar las condiciones de empleo de los empleados públicos, se trata en esencia de procedimientos de consulta exclusivamente entre las partes y de sistema de consulta en que intervienen órganos cuya vocación es conciliar puntos de vista o formular recomendaciones a los órganos de decisión con la ayuda de expertos o personalidades independientes" (OIT 2013a, párr. 162).

Estos procedimientos de consulta pueden materializarse en reuniones directas entre las partes, o dentro de un sistema de consultas más institucionalizado compuesto por órganos bipartitos o tripartitos permanentes, u organismos integrados por personas independientes. Corresponde a cada Estado adoptar el modelo de consulta más apropiado(5).

En segundo lugar, el contenido de los procedimientos de consulta debe cubrir los diversos temas que aborda las condiciones de empleo de los funcionarios públicos, inclusive puede ampliarse a las cuestiones de interés común de las partes. La Comisión de Expertos lo expresa en estos términos:

"En este sentido, la Comisión estima que debería ser posible abordar en las consultas toda medida administrativa o legislativa referente a las condiciones de trabajo de los empleados públicos. Lo anterior significa, en particular, que los proyectos de ley en la materia deberían ser objeto de consultas. Sin embargo, la Comisión señala que redunda en interés tanto de las autoridades como de las organizaciones sindicales de empleados públicos no limitar los temas de la consulta a las condiciones de trabajo y ampliarlos en cambio a las cuestiones de interés común, como el establecimiento de políticas del personal en la administración pública y los problemas de gestión y de recursos humanos que pueden plantearse como consecuencia de nuevas modalidades de organización del trabajo o de reestructuraciones" (OIT 2013a, párr. 222-223).

En tercer lugar, la representación de los funcionarios públicos en los procedimientos de consulta es más amplio que el establecido para las negociaciones colectivas. Esto proviene de la propia redacción del artículo 7 del Convenio No. 151. Para el caso de la negociación colectiva se señala a las organizaciones de los empleados públicos, mientras para los métodos distintos se refiere a los representantes de los empleados públicos. Como lo resalta la Comisión:

"Con arreglo al artículo 7, son las organizaciones de empleados públicos, es decir, las organizaciones que tienen por objeto fomentar y defender sus intereses, las que intervienen en la negociación, mientras que, en el contexto de otros métodos, la expresión utilizada tiene un alcance más amplio porque, en este caso, son los representantes de los empleados públicos los que participan en la determinación de las condiciones de trabajo. Dicho de otro modo, corresponde a los representantes de las organizaciones de los empleados públicos llevar a cabo las negociaciones, mientras que las consultas pueden tener lugar ya sea con organizaciones o representantes elegidos" (OIT 2013a, párr. 220).

En cuarto lugar, el Comité de Libertad Sindical ha planteado una serie de principios generales que deben guiar el procedimiento de consulta. Su celebración debe realizarse en un marco que reine la buena fe, la confianza y el respeto mutuo, de modo que las partes puedan expresar su punto de vista y discutirlo en profundidad, lo que permita llegar en lo posible a soluciones aceptables para las partes. Esto requiere tanto que no exista ningún tipo de discriminación sobre los representantes de las organizaciones y contar con la información pertinente sobre la materia que se va a abordar en la consulta.

Es importante que las autoridades públicas recaben las opiniones de las organizaciones de trabajadores para la preparación y la aplicación de la legislativa relativa a sus intereses. Para ello, el Comité resalta que la consulta debe producirse previamente a que el Gobierno someta un proyecto al Parlamento o establezca una política laboral, social o económica (OIT 2018, párr. 15171535).

En quinto lugar, en el procedimiento de consultas no existe un derecho de veto de los representantes de los funcionarios públicos porque las autoridades públicas siempre conservan la responsabilidad en la toma de decisiones (OIT 2013a, párr. 170).

Hay que tener presente que los procedimientos de consulta son válidos en los

(5) Hay una serie de ejemplos reseñados por la Comisión de Expertos. Véase Organización Internacional del Trabajo. 2013a. La negociación colectiva en la administración pública: un camino a seguir. Estudio General relativo a las relaciones laborales y la negociación colectiva en la administración pública. Ginebra: Oficina Internacional del Trabajo, 177-219. 
países donde no se ha reconocido el derecho de negociación colectiva de los funcionarios públicos. Sin embargo, es inválido sustituir la negociación colectiva por la consulta donde existe el reconocimiento del derecho. Un buen ejemplo lo encontramos en la fundamentación de la sentencia del Tribunal Constitucional peruano (TC) cuando otorga preferencia a la negociación colectiva sobre el procedimiento de consultas en base a la obligación estatal de fomentarla:

"Este Tribunal Constitucional considera que la negociación colectiva es el mecanismo adecuado y privilegiado para discutir las condiciones de trabajo o de empleo en el contexto de una relación laboral. Por ende la preferencia de la disposición que obliga el fomento de la negociación colectiva en el sector público frente a la disposición que faculta el uso de un método distinto a ella no solo permite garantizar de manera más efectiva y extensa posible el derecho a la negociación colectiva en el ámbito de la administración pública, sino que además permite cumplir adecuadamente el mandato contenido en el artículo 28 de la Constitución que establece de manera expresa la obligación del Estado de fomentarla" (TC 2016, fundamento jurídico 158).

El mencionado artículo 1 del Convenio No. 154 establece su aplicación en los servicios públicos al no establecer excepciones en su regulación. En su artículo 5 párrafo 1 exige que los Estados adopten las medidas adecuadas a las condiciones nacionales para fomentar la negociación colectiva.

El fomento del derecho de negociación colectiva en todas las ramas de la actividad económica por el Convenio No. 154 modifica la situación jurídica para aquellos Miembros de la OIT que implementan el procedimiento de consultas al amparo del Convenio No. 151. Una aplicación conjunta de ambas normas internacionales del trabajo conduce a que las consultas resulten insuficientes para cumplir con el mandato del Convenio 154. En otras palabras, la ratificación del Convenio No. 154 obliga al Estado a sustituir el procedimiento de consulta por la negociación colectiva de los funcionarios públicos de la administración del Estado.

La Comisión de Expertos lo apunta en los siguientes términos:

"A pesar que el reconocimiento del derecho de negociación colectiva de los funcionarios haya conocido un progreso manifiesto gracias a la adopción del Convenio No. 151, los Estados podían siempre evitar recurrir a la negociación colectiva y determinar las condiciones de empleo mediante otros métodos. Por esta razón, y a fin de permitir un reconocimiento más amplio de la negociación colectiva, el Convenio No. 154 y la Recomendación No. 163 sobre negociación colectiva adoptados en 1981 tienen como particularidad que abarcan tanto el sector privado como el sector público (salvo las fuerzas armadas y la policía). En lo que concierne a la administración pública, el Convenio No. 154 prevé únicamente que la legislación o la práctica nacionales podrán fijar modalidades particulares de aplicación del Convenio (párrafo 3 del artículo 1). El Estado Miembro que lo ratifique no puede, en consecuencia, seguir limitándose al método de consulta, como sucedía con el Convenio No. 151, y debe promover la negociación colectiva de las condiciones de trabajo y empleo (párrafo 1 de los artículos 2 y 3). De este modo, con la adopción del Convenio No. 154 , la comunidad internacional reconoce que la negociación colectiva constituye el medio privilegiado para reglamentar las condiciones de trabajo tanto para el sector público como para el sector privado" (OIT 2013a, párr. 50).

El órgano de control resalta que la potestad de las legislaciones o prácticas nacionales en fijar las modalidades particulares de la aplicación del Convenio No. 154 no puede interpretarse en conservar los procedimientos de consulta. El Estado Miembro que ratifica el Convenio No. 154 reconoce a la negociación colectiva como el único procedimiento para fijar las condiciones de trabajo y empleo entre las autoridades públicas y las organizaciones de empleados públicos.

En conclusión, las organizaciones de empleados públicos fijan sus condiciones de empleo con las autoridades públicas por medio de la negociación colectiva. En el caso de los funcionarios públicos de la administración del Estado, esto se puede producir por medio de la negociación colectiva u otros métodos de consulta, salvo que su Estado haya ratificado el Convenio No. 154 que prescribe la negociación colectiva como el único procedimiento.

3.1.1. Las materias de la negociación colectiva en el marco de las normas internacionales del trabajo

Las normas internacionales del trabajo establecen un marco general sobre las materias que se pueden abordar en la negociación colectiva. En el artículo 4 del Convenio No. 98 se señala que la finalidad de los procedimientos de la negociación colectiva es reglamentar las condiciones de empleo por medio de contratos colectivos. 
Luego, el artículo 7 del Convenio No. 151 establece que ya sea por los procedimientos de negociación o de cualesquiera otros métodos (los procedimientos de consulta), las autoridades públicas competentes y las organizaciones de empleados públicos o sus representantes pueden determinar las condiciones de empleo. Posteriormente, el artículo 2 del Convenio No. 154 señala que todas las negociaciones tienen por finalidad fijar las condiciones de trabajo y empleo, o regular las relaciones entre empleadores y trabajadores, o regular las relaciones entre empleadores o sus organizaciones y una organización o varias organizaciones de trabajadores, o lograr todos estos fines a la vez.

La regulación de las condiciones de empleo establecido en las dos primeras normas internacionales, luego se ve ampliado con el Convenio No. 154 con las condiciones de trabajo y empleo, además de las relaciones entre las partes negociadoras y al interior de las partes. En principio, podría entenderse que las normas internacionales del trabajo distinguen entre ambas condiciones (empleo y trabajo), pero que luego se integran. En realidad, desde un principio, se entendió que ambas condiciones eran reguladas por los convenios colectivos. Esto se evidencia con la Recomendación No. 91 sobre los contratos colectivos (1951), adoptada dos años después del Convenio No. 98, donde define la expresión contratos colectivos como "todo acuerdo escrito relativo a las condiciones de trabajo y de empleo (...)", es decir ambas condiciones pueden celebrase dentro de una negociación colectiva. Esto abona la interpretación de que ambas condiciones se utilizan indistintamente como materias de la negociación colectiva.

El respaldo a esta interpretación provino del Informe de la Conferencia Internacional del Trabajo de 1951, donde equiparan de manera conjunta condiciones de trabajo y de empleo, como después lo formula el Convenio No. 154: "las partes gozan de plena libertad para determinar, dentro de los límites de las leyes y del orden público, el contenido de esos acuerdos y también, por tanto, para convenir cláusulas relativas a todas las cuestiones de trabajo y de vida, comprendiendo especialmente medidas sociales de todas clases" (OIT 1951, 53-54).

También los órganos de control de la OIT asumieron esta posición apoyándose en el referido Informe:

"La determinación de las materias que pueden ser objeto de negociación y su alcance o la determinación de su contenido no es tarea fácil, pues depende de lo que se entienda por esas condiciones y las relaciones entre las partes como contenido de la negociación. Durante los trabajos preparatorios del Convenio No. 154, realizados en la Comisión de la negociación colectiva, los miembros trabajadores subenmendaron una enmienda que habían presentado en relación con el objeto de la negociación colectiva, mediante la supresión de la referencia a las "condiciones de vida" y a las "medidas sociales de todas clases" y la inserción de la fórmula "fijar las condiciones de trabajo y empleo". No obstante, pidieron a la Comisión que confirmase la interpretación de los términos "condiciones de trabajo y empleo" que ya se había dado en 1951 (...). La enmienda fue adoptada en su versión enmendada y la Comisión dio su acuerdo para que se confirmase la interpretación (...). La noción de condiciones de trabajo utilizada por los órganos de control de la OIT, que se ajusta a esta interpretación, no se limita a los temas tradicionales (jornada laboral, horas extraordinarias, períodos de descanso, salarios, etc.), sino que cubre también otras cuestiones (por ejemplo, "materias que normalmente pertenecen a las esferas de las condiciones de empleo", como los ascensos, los traslados o las supresiones de puestos sin previo aviso)" (OIT 2013a, párr. 314).

Sobre la base de esta interpretación, los órganos de control de la OIT han venido precisando el contenido de las condiciones de trabajo y empleo como materia de la negociación colectiva, en particular dentro de los servicios públicos.

La Comisión de Expertos señala que la negación a la negociación libre de los salarios y las condiciones de empleo es violatoria del artículo 4 del Convenio No. 98:

"Según la Comisión, el derecho a negociar libremente con los empleadores y sus organizaciones sobre salarios y condiciones de empleo constituye un aspecto fundamental de la libertad sindical. Los sindicatos deben poder ejercer ese derecho sin que el mismo sea indebidamente obstaculizado por restricciones legales. La adopción de medidas restrictivas viola el principio según el cual las organizaciones de trabajadores y de empleadores tienen derecho a organizar sus actividades y formular su programa de acción; además es incompatible con el principio del fomento de la negociación colectiva. Por eso no es compatible con el artículo 4 del Convenio No. 98 excluir de la negociación colectiva cuestiones relativas a condiciones de trabajo, exigir la aprobación previa de un convenio colectivo para que pueda aplicarse y permitir que sea declarado 
nulo por ser contrario a la política económica del gobierno. La Comisión recuerda que un sistema de homologación sólo es admisible en la medida en que ésta no pueda ser rehusada más que por cuestiones de forma, o bien en el caso de que las disposiciones del Convenio colectivo no estuvieran de acuerdo con las normas mínimas establecidas por la legislación laboral" (OIT 1983, párr. 311).

Respecto al artículo 7 del Convenio No. 151, la Comisión subraya que los salarios o las compensaciones económicas están incluidos dentro de las condiciones de empleo. Por ejemplo, en su Observación a Perú donde una ley prohibió la negociación salarial en los servicios públicos le señala:

"Contrasta con preocupación que las mencionadas disposiciones legislativas excluyen cualquier mecanismo de participación, incluida la negociación colectiva en el conjunto del sector público, lo cual es contrario al artículo 7 que, al referirse a la negociación o participación de las organizaciones de los empleados públicos en la determinación de las condiciones de empleo, incluye los aspectos económicos de estas últimas" (el subrayado es mío) (OIT 2015, 136).

También el Comité de Libertad Sindical se ha pronunciado al respecto en similares términos:

"Las cuestiones que pueden ser objeto de la negociación colectiva incluyen el tipo de convenio que se ofrezca a los trabajadores o el tipo de convenio colectivo que haya de negociarse en el futuro, así como los salarios, prestaciones y subsidios, la duración del trabajo, las vacaciones anuales, los criterios de selección en caso de despido, un alcance del convenio colectivo, el otorgamiento de facilidades a los sindicatos, que incluyan un acceso al lugar de trabajo más amplio que el previsto en la legislación, etc.; esas cuestiones no deberían excluirse del ámbito de la negociación colectiva en virtud de la legislación, o como en este caso, por sanciones económicas y penas severas en caso de incumplimiento de las disposiciones del código y de las directrices" (OIT 2018, párr. 1291).

Las condiciones de trabajo y empleo cubren un amplio espectro de materias de las relaciones laborales: los salarios, las compensaciones económicas, la jornada de trabajo, las vacaciones, la seguridad y la salud en el trabajo, las facilidades a los sindicatos y sus representantes, etc.

Sin embargo, las particularidades propias del empleo público también significan limitar o restringir las materias en la negociación colectiva de los servicios públicos. El pronunciamiento de la Comisión de Investigación y de Conciliación en materia de Libertad Sindical sobre Japón de 1966 se convirtió en el pilar sobre el tema:

"Existen ciertas cuestiones que corresponden, evidentemente, de modo primordial o esencial, a la dirección y funcionamiento de los asuntos del gobierno; estas cuestiones pueden considerarse de modo razonable fuera del alcance de la negociación. Es igualmente claro que algunas otras cuestiones son primordial o esencialmente cuestiones que se refieren a condiciones de empleo. Pero es preciso reconocer que existen muchas cuestiones que afectan tanto a la dirección y al funcionamiento como a las condiciones de empleo" (OIT 1966, párr. 2229).

El sustento de esta restricción proviene de la condición de empleador del Estado, la negociación no debe socavar la capacidad del empleador en la toma de decisión que le es exclusiva, como el poder de dirección. Asimismo, también se encuentran restringidas las materias que afecten el orden público, como cláusulas discriminatorias. Esas materias restringidas de la negociación colectiva son abordadas por los órganos de control de la OIT, por ejemplo, la Comisión afirma:

"Los órganos de control han admitido algunas restricciones en relación con los temas que pueden ser objeto de negociación colectiva. Han determinado, por ejemplo, que las prerrogativas en materia de gestión propias de los empleadores (como la asignación de tareas y la contratación de personal) podrían excluirse de las cuestiones negociables. Además, cabría prohibir determinados temas por motivos de orden público, como las cláusulas discriminatorias, las cláusulas de seguridad sindical y las cláusulas que sean contrarias al nivel mínimo de protección contemplado en la legislación" (OIT 2012, párr. 216).

En conclusión, las condiciones de trabajo y de empleo, las cláusulas sobre las relaciones entre las partes y al interior de las partes conforman las materias de la negociación colectiva en los servicios públicos.

3.1.2. La restricción presupuestal sobre la negociación colectiva en los servicios públicos

El presupuesto estatal organiza los ingresos y los gastos públicos, de forma tal que asegure el equilibrio y evite el déficit. Por 
ello, el principio de equilibrio presupuestal asegura que los gastos deben estar respaldados por una partida presupuestaria que cuenta con los recursos fijados para dicha finalidad, sin ésta no pueden ser sufragados. El presupuesto suele ser aprobado por el parlamento de los Estados, aunque en su elaboración el rol principal le corresponde al Gobierno.

El Estado, en su faceta de empleador, está sujeto a lo establecido en el presupuesto para afrontar los gastos públicos que suponen los costos laborales de la planilla de empleados públicos. Cualquier incremento de este gasto debe venir acompañado de un recurso presupuestario, por lo que las legislaciones suelen condicionar los incrementos salariales o las compensaciones económicas a la existencia de la partida presupuestaria. En otras palabras, la celebración de acuerdos o convenios colectivos en los servicios públicos se encuentra condicionado a lo establecido en las leyes presupuestales. Por ello, se alienta que la negociación colectiva en los servicios públicos se realice previo a la elaboración del presupuesto, de modo que pueda incorporarse a él.

Los órganos de control de la OIT se han pronunciado en reiteradas ocasiones sobre la restricción presupuestaria y la negociación colectiva en el sector público, por lo que podemos contar con una apreciación precisa de su posición al respecto.

Sobre la base de las particularidades de la negociación colectiva de los empleados públicos y la restricción presupuestal, la Comisión de Expertos plantea una serie de alternativas para asegurar una armonía entre el ejercicio del derecho fundamental y el presupuesto:

"Aun cuando el principio de la autonomía de las partes en la negociación colectiva conserva su validez por lo que se refiere a los funcionarios y empleados públicos amparados por el Convenio No. 151, éste ha de aplicarse con cierto grado de flexibilidad, dadas las características particulares de la administración pública señaladas anteriormente. Por esta razón, a juicio de la Comisión son compatibles con el Convenio las disposiciones legislativas que habilitan al Parlamento o al órgano competente en materias presupuestarias para fijar un "abanico" salarial que sirva de base a las negociaciones, o establecer una "asignación" presupuestaria global fija en cuyo marco las partes pueden negociar las cláusulas de índole pecuniaria o normativa (por ejemplo, la reducción del tiempo de trabajo u otros arreglos en materia de condiciones de empleo, la regulación de los aumentos de salario en función de los diferentes niveles de remuneración, o el establecimiento de dispositivos para escalonar los reajustes), o incluso las disposiciones que confieren a las autoridades públicas que tengan atribuidas responsabilidades financieras el derecho de participar en las negociaciones colectivas junto al empleador directo, en la medida en que dejen un espacio significativo a la negociación colectiva. Es fundamental, empero, que los trabajadores y sus organizaciones puedan participar plenamente y de manera significativa en la determinación de ese marco global de negociación, lo que implica, en particular, que dispongan de todas las informaciones financieras, presupuestarias o de otra naturaleza que les sirvan para evaluar la situación con pleno conocimiento de causa" (OIT 1994, párr. 263).

El órgano de control de la OIT reconoce que la negociación colectiva en la administración pública tiene importantes diferencias respecto a la que se produce en la actividad privada, pero no significa que sus particularidades eliminan o prohíben la autonomía colectiva, sino que plasman límites. El presupuesto estatal es uno de esos límites naturales de la negociación colectiva del sector público, en razón que el Estado moderno diseña su actuación pública en función a los recursos económicos que dispone, de modo que los gastos, el cual incluye las remuneraciones de los servidores públicos, deben estar previamente establecidos para asegurar su desembolso.

Así la negociación colectiva en la administración pública debe desenvolverse teniendo como premisa el presupuesto estatal (OIT 2018: párrafo 1485). Por ello, también el Comité de Libertad Sindical reconoce expresamente que la normativa presupuestaria es un límite en la fijación de los salarios de los trabajadores estatales, aunque con la suficiente amplitud que no la impida:

"En la medida en que los ingresos de las empresas y entidades públicas dependan de los presupuestos del Estado, no sería objetable que -después de una amplia discusión y consulta entre los empleadores y las organizaciones sindicales interesadas en el seno de un sistema que cuente con la confianza de las partes- se establecieran topes salariales en las leyes de presupuesto del Estado, ni tampoco que el Ministerio de Economía y Hacienda realice un informe previo antes de que se inicie a la negociación colectiva con miras a que se respeten dichos topes" (OIT 2018, párr. 1486).

El presupuesto público es una restricción válida del derecho de negociación colectiva 
en los servicios públicos, pero no puede interpretarse como una prohibición. En otras palabras, las leyes presupuestales enmarcan el espacio de negociación entre las autoridades púbicas y los representantes de las organizaciones de empleados públicos, lo suficientemente amplia que permita el acuerdo. Eso explica que los órganos de control de la OIT pongan el énfasis en que la negociación se desenvuelva previa a la aprobación del presupuesto, porque eso facilita el acuerdo, en vez de implementarla con posterioridad que fija límites difíciles de superar.

\section{Conclusiones}

El Convenio No. 98 establece que los empleados públicos gozan del derecho de negociación colectiva, con la excepción de los funcionarios públicos de la administración del Estado. El Convenio No. 151 extiende una modalidad de este derecho a los funcionarios públicos de la administración del Estado, con excepción de los funcionarios de alto nivel (poder de decisión, cargos directivos y puestos de confianza). Una categoría especial son los miembros de las fuerzas armadas y la policía que le corresponde a la normativa nacional definir el alcance de las garantías previstas por las normas internacionales del trabajo.

Los órganos de control de la OIT han cumplido una valiosa tarea de constreñir la definición de funcionario público de la administración del Estado de modo que no excluya arbitrariamente a empleados públicos del ejercicio del derecho de negociación colectiva. Sus pronunciamientos son una evaluación caso por caso que ha conformado un listado abierto. Los parlamentarios, los magistrados y las autoridades públicas que ocupan cargos de carácter político por elección o por nombramiento de ubican en la categoría de funcionarios de alto nivel. Por el contrario, los trabajadores de la enseñanza pública, la salud pública, los empleados municipales, los trabajadores de las empresas públicas y las instituciones públicas autónomas, el personal de establecimientos penitenciarios, el personal civil de las fuerzas armadas y la policía, tienen el derecho de negociación colectiva.

También el Convenio No. 151 establece como procedimiento predominante la negociación colectiva, pero en el caso de los funcionarios públicos de la administración del Estado también se permite alternativamente otros métodos (el procedimiento de consulta) que posibilitan participar a las organizaciones de los empleados públicos en la fijación de las condiciones de empleo. En el caso de los empleados públicos no cabe la aplicación de los procedimientos de consulta bajo el marco del Convenio No. 98. Asimismo, la ratificación del Convenio No. 154 conduce a que el procedimiento de consulta debe ser sustituido por la negociación colectiva en los funcionarios públicos de la administración del Estado.
Las normas internacionales del trabajo establecen que son materias de la negociación colectiva la regulación de las condiciones de trabajo y empleo, que incluye los salarios y la compensación económica. Sin embargo, no son materias de negociación colectiva aquellas que afecten el poder de dirección del Estado como empleador y las normas de orden público. Asimismo, la restricción presupuestaria es un límite válido en el derecho de negociación colectiva de los servicios públicos.

\section{Referencias bibliográficas}

Comité de Libertad Sindical. 1988a. Informe 139, caso No. 725, 1974. Ginebra: Oficina Internacional del Trabajo.

1988b. Informe 143, caso No. 764 , 1974. Ginebra: Oficina Internacional del Trabajo.

1988c. Informe 256, caso No. 1391 , junio 1988. Ginebra: Oficina Internacional del Trabajo.

1988d. Informe 259, caso No. 1429, noviembre 1998. Ginebra: Oficina Internacional del Trabajo.

1988e. Informe 304, caso No. 1882 , marzo 1997. Ginebra: Oficina Internacional del Trabajo.

1988f. Informe 338, caso No. 2253, noviembre 2005. Ginebra: Oficina Internacional del Trabajo.

Organización Internacional del Trabajo. 1949. Aplicación de los principios del derecho de organización y de negociación colectiva, informe IV (2). Ginebra: Oficina Internacional del Trabajo.

1951. Relaciones Profesionales, informe $V$ (2), Conferencia Internacional del Trabajo. Ginebra: Oficina Internacional del Trabajo.

1966. Libertad sindical en el sector público en Japón. Informe de la Comisión de Investigación y de Conciliación en materia de Libertad Sindical relativo a las personas empleadas en el sector público en el Japón. Ginebra: Oficina Internacional del Trabajo. 
1977. Actas de la Conferencia Internacional del Trabajo, $63^{\circ}$ reunión. Ginebra: Oficina Internacional del Trabajo.

1983. Libertad sindical y negociación colectiva. Estudio General acerca de la aplicación de los convenios sobre libertad sindical y sobre el derecho de sindicación y de negociación colectiva, así como del convenio y de la recomendación sobre las organizaciones de trabajadores rurales. Ginebra: Oficina Internacional del Trabajo.

1994. Libertad Sindical y Negociación Colectiva. Estudio General sobre la aplicación de los convenios sobre libertad sindical y sobre el derecho de sindicación y de negociación colectiva. Ginebra: Oficina Internacional del Trabajo.

2011. Aplicación de las normas internacionales del trabajo, 2011 (1). Informe de la Comisión de Expertos en Aplicación de Convenios y Recomendaciones. Ginebra: Oficina Internacional del Trabajo.

2012. Dar un rostro humano a la globalización. Estudio General sobre los convenios fundamentales relativos a los derechos en el trabajo a la luz de la Declaración de la OIT sobre la justicia social para una globalización equitativa, 2008. Ginebra: Oficina Internacional del Trabajo.

2013a. La negociación colectiva en la administración pública: un camino a seguir. Estudio General relativo a las relaciones laborales y la negociación colectiva en la administración pública. Ginebra: Oficina Internacional del Trabajo.

2013b. Aplicación de las normas internacionales del trabajo, 2013 (1). Informe de la Comisión de Expertos en Aplicación de Convenios y Recomendaciones. Ginebra: Oficina Internacional del Trabajo.

2015. Aplicación de las normas internacionales del trabajo 2015 (1). Informe de la Comisión de Expertos en Aplicación de Convenios y Recomendaciones. Ginebra: Oficina Internacional del Trabajo.

2018. La Libertad Sindical. Recopilación de decisiones y principios del Comité de Libertad Sindical del Comité de Administración de la OIT, $6^{a}$ edición revisada. Ginebra: Oficina Internacional del Trabajo.

Tribunal Constitucional del Perú. 2016. Caso Ley de Servicio Civil. Sentencia de 26 de abril de 2016 recaída en los Expedientes No. 0025-2013-PI/TC, 0003-2014-PI/TC, 0082014-PI/TC y 0017-2014-PI/TC. 